\title{
Endonasal Endoscopic Approach for Skull Base Neurofibroma: Is It Viable?
}

\author{
${ }^{1}$ Ashok Gupta, ${ }^{2}$ MK Tiwari, ${ }^{3}$ Neha Chauhan, ${ }^{4}$ Navjot Kaur, ${ }^{5}$ Vaiphei Kim
}

\begin{abstract}
Anterior skull base and sinonasal schwannomas are rare entities. Earlier, safest way to remove these tumors, with best success rates, was open craniofacial surgery but recently with introduction of endoscopic endonasal approach; complete resection of these rare entities is possible. We present one such case of skull base neurofibroma which was resected in entirety via a purely endoscopic endonasal approach.
\end{abstract}

Keywords: Endonasal, Endoscopic, Schwannoma, Skull base.

How to cite this article: Gupta A, Tiwari MK, Chauhan N, Kaur N, Kim V. Endonasal Endoscopic Approach for Skull Base Neurofibroma: Is It Viable?. Clin Rhinol An Int J 2015;8(2):72-75.

\section{Source of support: Nil}

Conflict of interest: None

\section{INTRODUCTION}

Peripheral nerve sheath tumors (schwannomas and neurofibromas) of the skull base are rare entities. This lesion may be seen within the sinonasal tract and some may have an intracranial extension. These are usually associated with neurofibromatosis (type I). Surgical removal of skull base tumors can result in a cure for many patients. Traditionally, open craniofacial approach was considered as the safest approach which had the best chance of survival. In recent years, however, endoscopic endonasal approach for complete removal of skull base tumor is advocated. Here, we report a complete removal of the tumor of anterior skull base via endonasal route.

\footnotetext{
${ }^{1}$ Professor and Head, ${ }^{2,5}$ Professor, ${ }^{3,4}$ Senior Resident

1,3,4 Department of Otorhinolaryngology and Head and Neck Surgery, Postgraduate Institute of Medical Education and Research, Chandigarh, India

${ }^{2}$ Department of Neurosurgery, Postgraduate Institute of Medical Education and Research, Chandigarh, India

${ }^{5}$ Department of Pathology, Postgraduate Institute of Medical Education and Research, Chandigarh, India
}

Corresponding Author: Ashok Gupta, Professor and Head Department of Otorhinolaryngology and Head and Neck Surgery, Postgraduate Institute of Medical Education and Research, Chandigarh, India, e-mail: drashokpgi@hotmail.com

\section{CASE REPORT}

A 25 years female presented to outpatient services of Department of Otorhinolaryngology-Head and Neck Surgery, Postgraduate Institute of Medical Education and Research, Chandigarh with complaints of left sided facial pain since 20 years. The pain was intermittent and episodic. The episode lasted for 15 to 20 minutes and was mild to moderate in intensity. It was more on the frontal region on left side and extended to the left eye and face. It was relieved with medication in the form of pain killers. There was no history of nasal discharge, altered smell, decreased or double vision, seizures, fever, neck rigidity of any focal neurological deficit. There was no significant past medical or surgical, family or personal history.

On examination, her ENT examination was grossly normal. Nasal endoscopy was done which showed no abnormality.

Contrast-enhanced magnetic resonance imaging showed a well-defined extra-axial lobulated space occupying lesion along the basifrontal region centered in the left olfactory groove with erosion of the cribriform plate with extension into the left nasal cavity. It measured approximately $1.6 \times 2.1 \times 1.5 \mathrm{~cm}$. The mass appeared as isointense to cortex on coronal images (Figs 1 to 5).

Sagittal (Fig. 3) contrast-enhanced T1-weighted image and T2-weighted image showing isointense mass (Fig. 4) and isodense on contrast-enhanced computed tomography image.

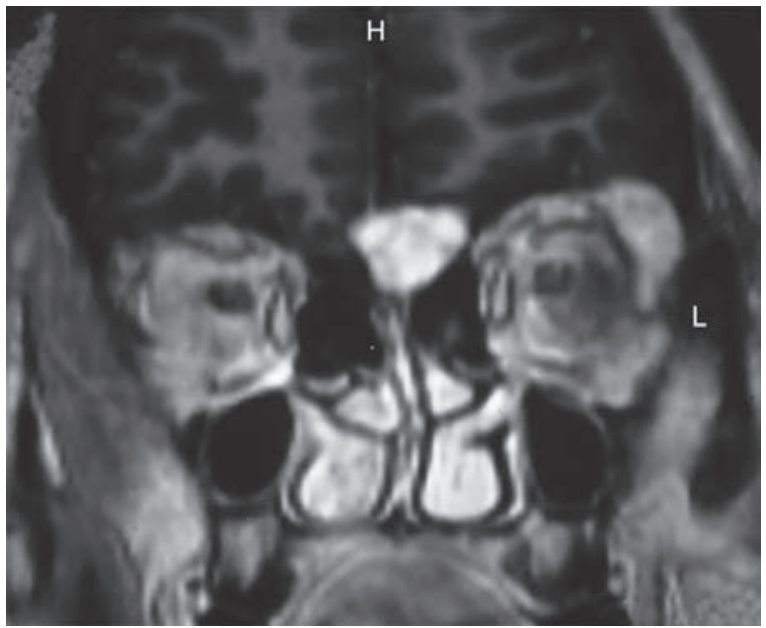

Fig. 1: Contrast-enhanced magnetic resonance imaging coronal cut showing a well-defined extra-axial space occupying hyperintense lesion along the basifrontal region centered in the left olfactory groove 


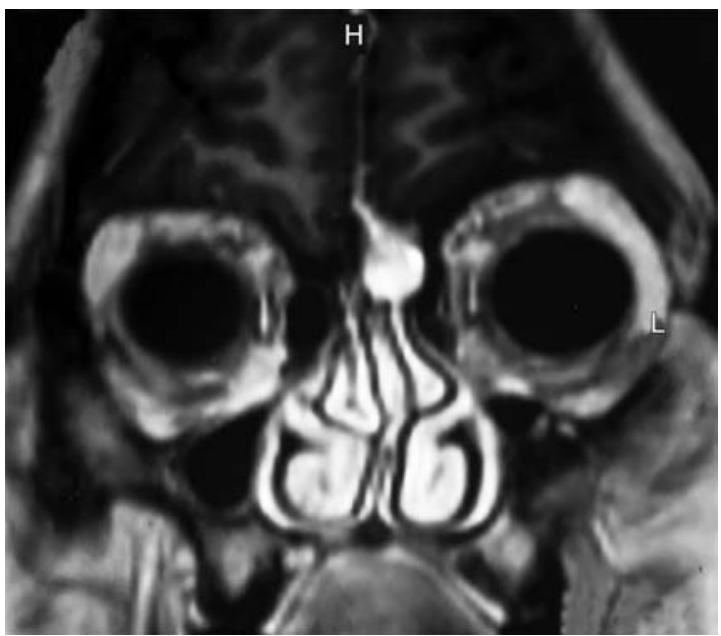

Fig. 2: Contrast-enhanced magnetic resonance imaging coronal cut showing an extra-axial hyperintense lobulated lesion

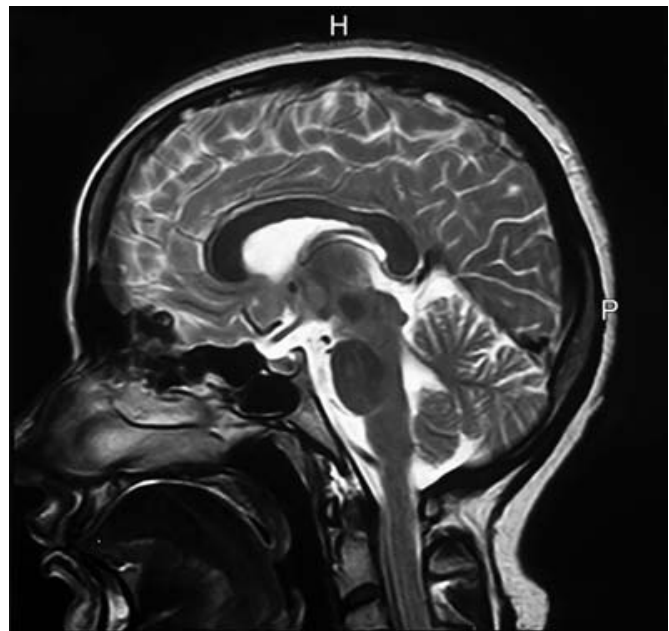

Fig. 4: T2-weighted image showing isointense mass

The patient was planned for endoscopic endonasal resection of the tumor under general anesthesia.

The patient was taken up for surgery under general anesthesia. After decongesting the nasal cavity, septo-

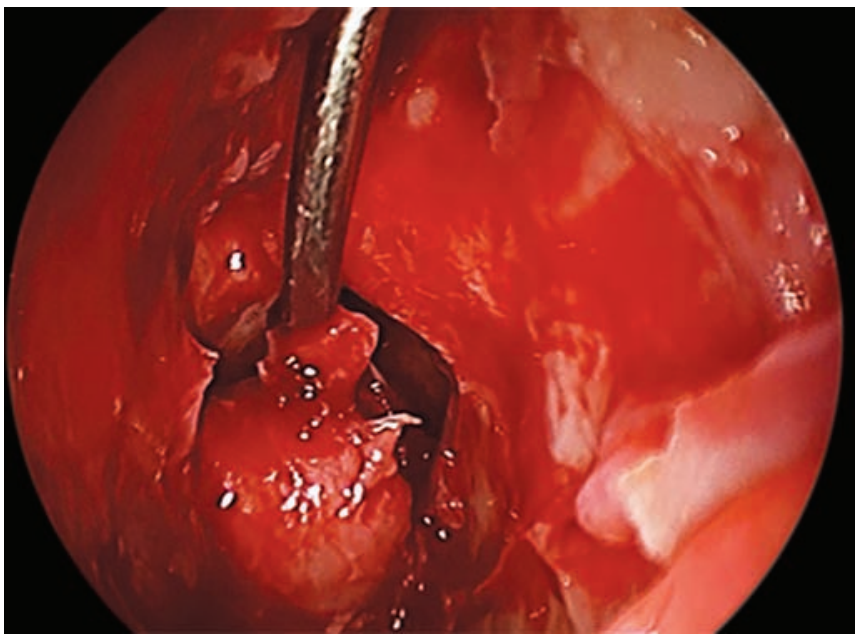

Fig. 6: A $2 \times 2 \mathrm{~cm}$ firm intracranial extradural mass was seen in the region of left cribriform plate

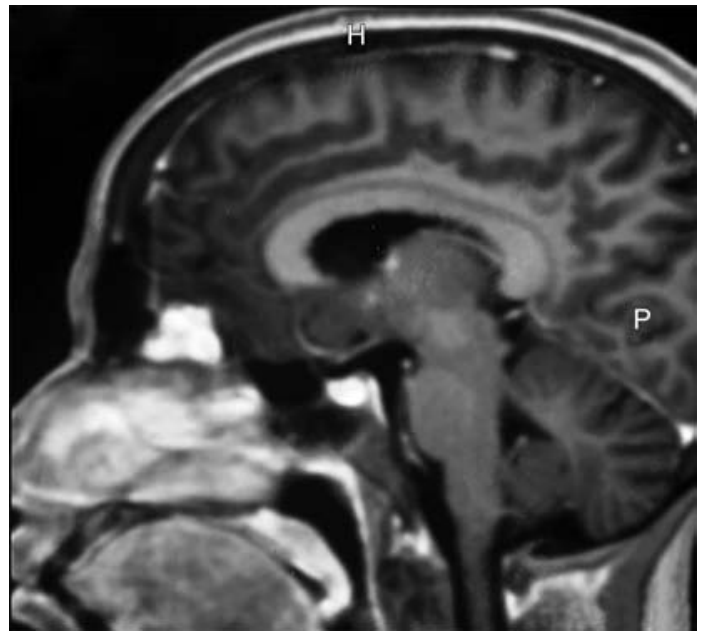

Fig. 3: Sagittal contrast-enhanced T1-weighted image showing hyperintense

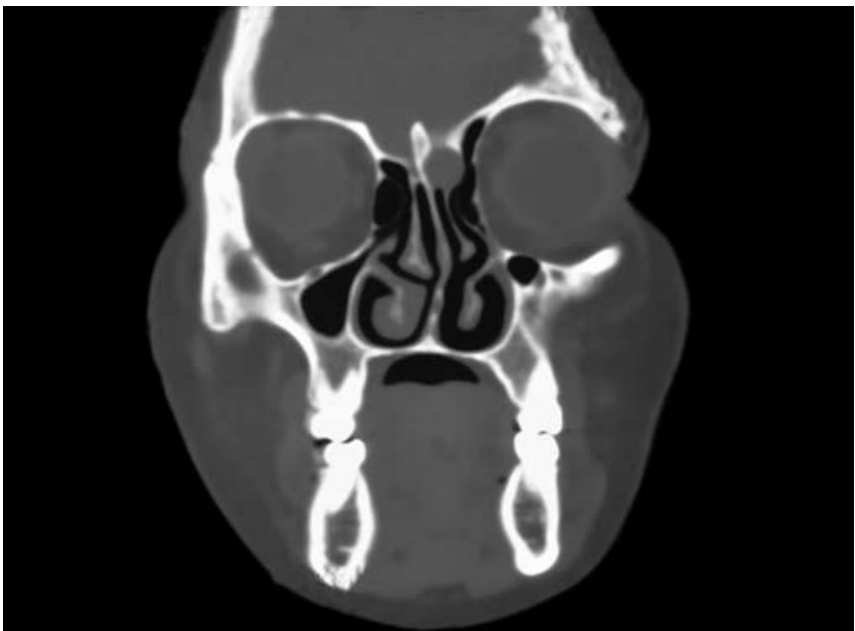

Fig. 5: Coronal cut computed tomography image showing isodense mass

plasty was done. Left sided uncinectomy and wide middle meatal antrostomy was done. Following this anterior and posterior ethmoidectomy was done. Skull base was delineated by removing superior part of middle turbinate.

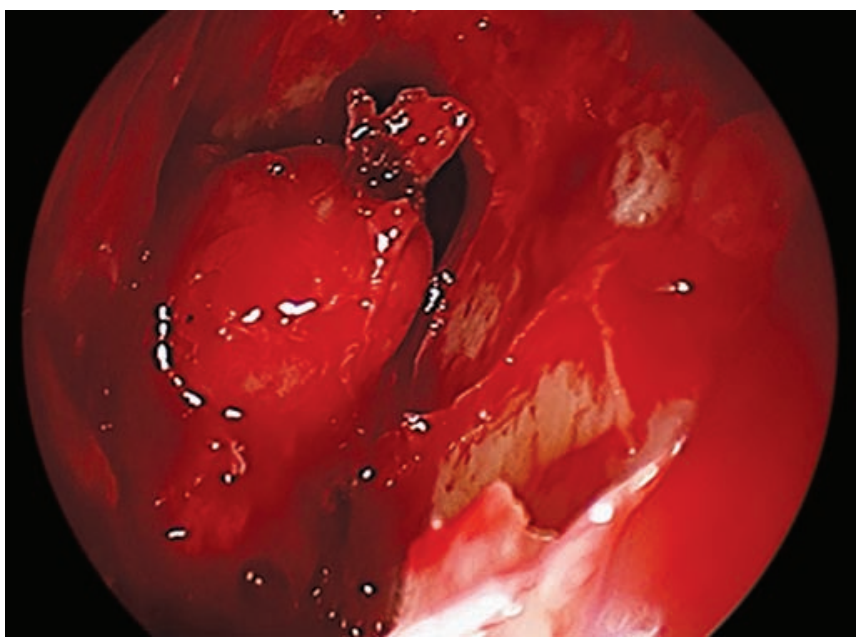

Fig. 7: Multilobulated mass delineated in the region of left cribriform plate 


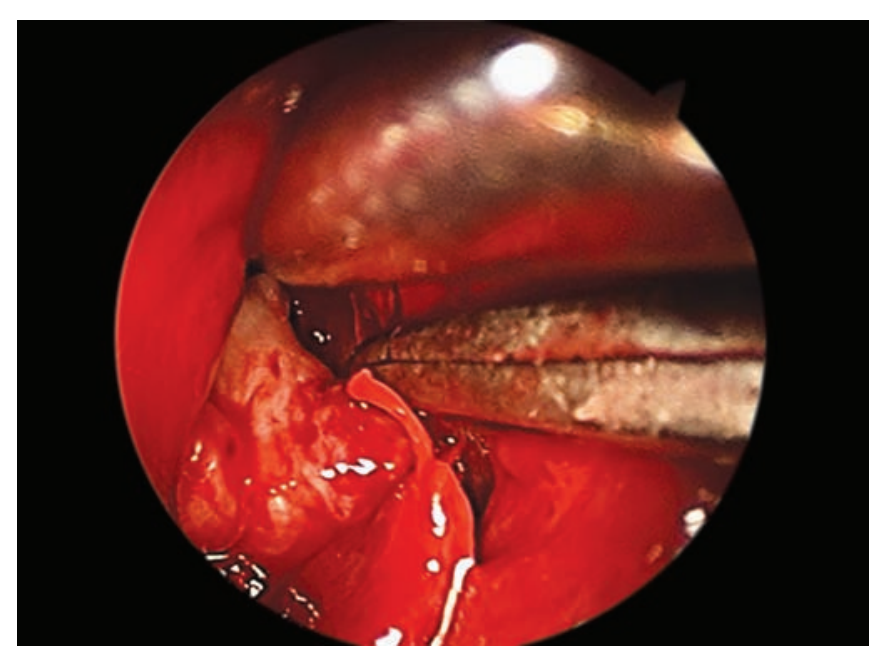

Fig. 8: Mass is being dissected and freed from all the attachments

A $2 \times 2 \mathrm{~cm}$ firm multilobulated, non-bleeding, intracranial extradural mass was seen in the region of left cribriform plate (Figs 6 to 8).

The mass was freed from all the attachments and removed in toto and sent for histopathology (Figs 9 and 10).

Intraoperatively the tumor was firm, multilobulated intracranial extradural mass arising from left cribriform plate and was removed in toto (Fig. 10).

The skull base defect was examined for any bleeding. The skull base defect was repaired using with multiple layers of rectus femoris muscle, fascia lata, surgical, fascia lata, sugicel, fascia lata and nasal packing was done (Fig. 11).

Pack was removed on postoperative day 4 and gentle nasal suction was done. She was started on intravenous antibiotics and absolute bed rest.

Postoperatively patient had symptomatic improvement in pain and no cerebrospinal fluid leak.

Histopathology examination showed the encapsulated mass in low power. The nerve twigs are highlighted with arrows along the capsule $(\mathrm{H} \& \mathrm{E} \times 50)$. The same

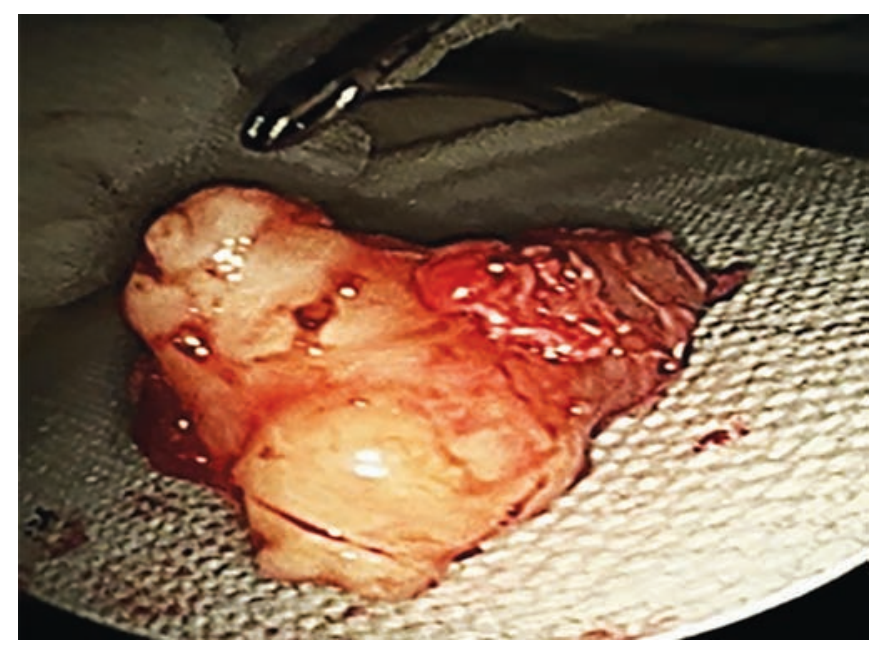

Fig. 10: $1.8 \times 2.2 \times 1.4 \mathrm{~cm}$ firm mass removed in toto

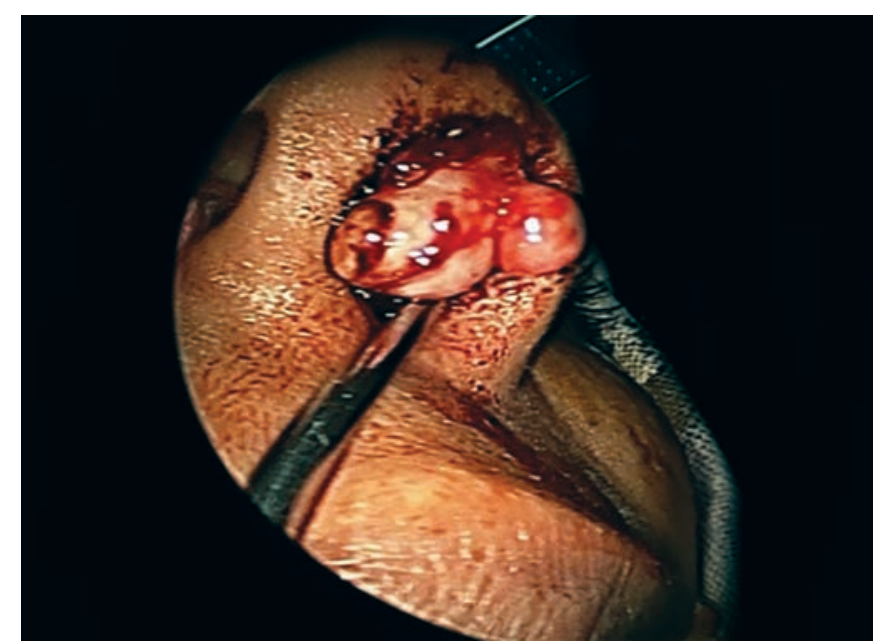

Fig. 9: Mass is being removed in toto

figure also bears an inset to highlight the entrapped nerve twigs by S-100 immunohistochemistry staining. (Peroxidase antiperoxidase, $\times 40$ (Fig. 12A). Higher power photomicrograph of the same mass to show the wispy spindle shaped cells with abundant amount of intracellular collagen. Many of the nuclei show classic buckling appearance of a neurofibroma (H\&E × 400) (Fig. 12B).

\section{DISCUSSION}

Neurofibromas are slow growing benign nerve sheath tumors that originate from the peripheral nervous system. They arise from the non-myelinating schwann cells. These are usually found in patients with neurofibromatosis, an autosomal dominant disease. On occasion, an isolated neurofibroma can be seen without associated neurofibromatosis. The solitary neurofibromas are more common in gastrointestinal system. ${ }^{1,2}$ Nerve sheath tumors of anterior skull base are very rare and preoperatively may be misdiagnosed as esthesioneuroblastoma, meningioma or hemangiopericy toma $\mathrm{a}^{3-5}$ due to its location or contrast uptake in computed tomography.

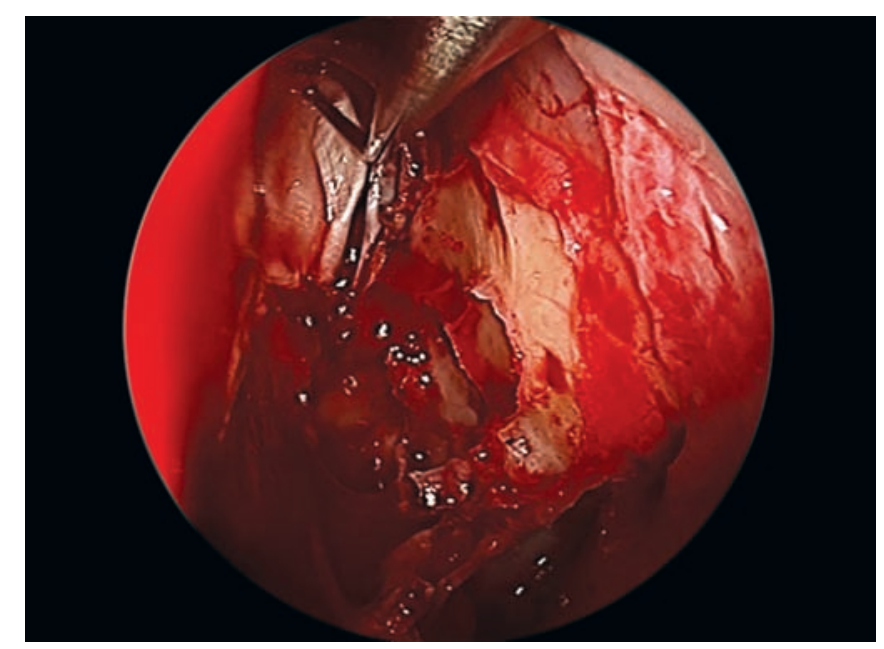

Fig. 11: Repair of skull base defect 


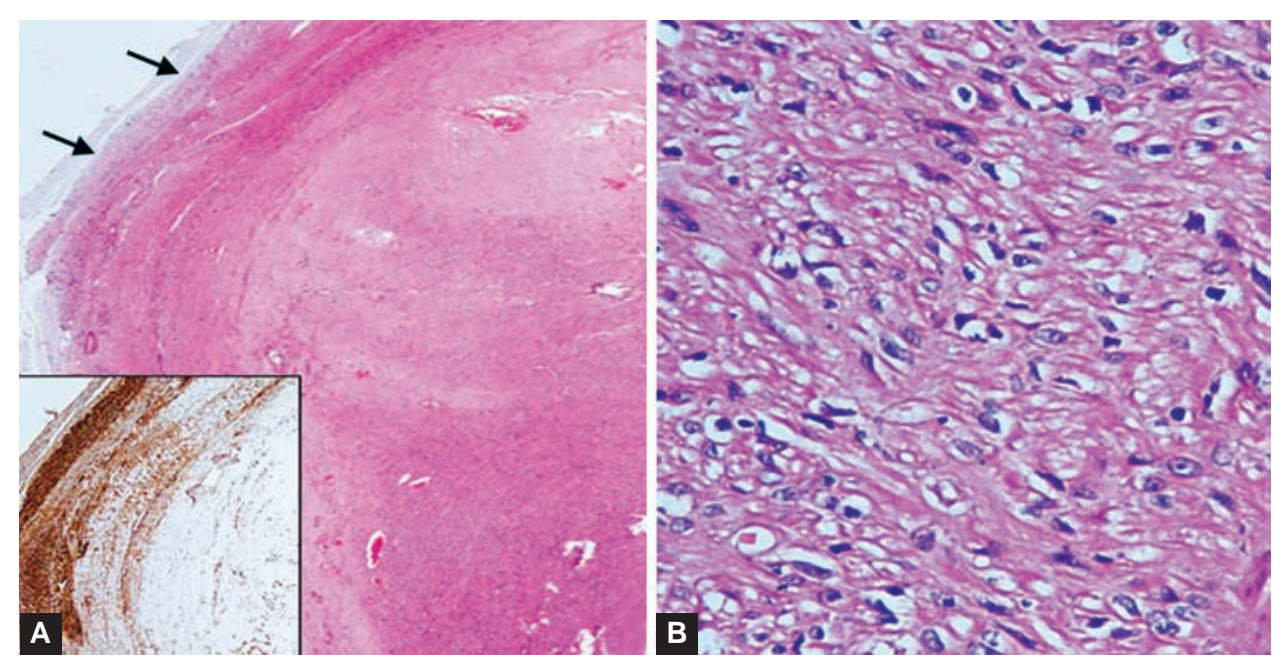

Figs 12A and B: Histopathology report came out to be neurofibroma

Histologically these tumors are non-encapsulated with proliferation of all elements of peripheral nerves. Schwann cells with wire like collagen fibrils, stromal mucosubstances, mast cells, Wagner-Meissner corpuscles, pacinian corpuscles, axons which highlight with silver or acetylchonisesterase stain.

These tumors are capable of causing large compression of local structures and can cause expansion and erosion of the adjacent bone, as was seen in our case.

The symptomatology is usually non-specific like epistaxis (more in nasal fossa and ethomoidal sinus), nasal obstruction, facial pain (especially maxillary tumors), hemorrhagic necrosis and thrombi are also responsible for misdiagnosing them as vascular tumors like angiofibroma or fibrotic nasal polyps. Thus, when not in association with von Recklinghausen's disease, they are difficult to diagnose.

Clinically the signs and symptoms depend on the site and size of the tumor and involvement of adjacent structures. ${ }^{6}$ In our case the only symptom that was seen was hemifacial pain and paresthesia which resolved completely upon removal of the tumor.

Surgical resection is the treatment of choice for neurofibroma involving anterior skull base and paranasal sinuses. The goal of the surgery is gross total resection. ${ }^{7,8}$ Before planning of the surgery an MRI should be done to assess the complete extent of disease and if possible the nerve involved.

Approach for the tumor depends upon the site and size of the tumor and expertise of the operating surgeon. For larger tumors combined open approaches, such as bifrontal craniotomy or perhaps even a combined transcranial and endonasal approach can be considered. In our case we used the 'two-nostril-four-hand' endoscopic approach. Anterior skull base was exposed and gross total resection was done successfully.

\section{CONCLUSION}

Neurofibroma of the anterior skull base is a very rare entity and its surgical removal via endonasal route is possible. The scope of endocope should not be underestimated in removal of the skull base lesions, no matter how large. This tool for minimal invasion surgeries can overcome all the limitations of the extensive procedures like craniotomies and reduce postoperative morbidities and increase life quality.

\section{REFERENCES}

1. Tsai PJ, Liu KY, Wang SE, Shyr YM, Su CH, Chen TH. 'Solitary neurofibroma of the pancreas body not associated with type 1 neurofibromatosis'. J Chinese Med Assoc 2012;75(3): 132-135.

2. Hindy P, Parvin R, Hanna K, Andrawes S, Gress F, Goodman A. 'An isolated neurofibromal polyp of the colon'. Case Reports in Gastroenterol 2012;6(1):58-62.

3. Liu JK, Christiano LD, Patel SK, et al. Surgical nuances for removal of olfactory groove meningiomas using the endoscopic endonasal transcribriform approach. Neurosurg Focus 2011;30:E3.

4. Dahodwala MQ, Husain Q, Kanumuri VV, et al. Management of sinonasal hemangiopericytomas: a systematic review. Int Forum Allergy Rhinol 2013;3(7):581-587.

5. Tessema B, Eloy JA, Folbe AJ, et al. Endoscopic management of sinonasal hemangiopericytoma. Otolaryngol Head Neck Surg 2012;146(3):483-486.

6. Perzin KH, Panyu H, Wechter S. 'Nonepithelial tumors of the nasal cavity, paranasal sinuses and nasopharynx'. A clinicopathologic study. XII: schwann cell tumors (neurilemoma, neurofibroma, malignant schwannoma). Cancer 1982;50(10):2193-2202.

7. Sunaryo PL, Svider PF, Husain Q, et al. Schwannomas of the sinonasal tract and anterior skull base: a systematic review of 94 cases. Am J Rhinol Allergy 2014;28(1):39-49.

8. Liu JK, Eloy JA. Expanded endoscopic endonasal transcribriform approach for resection of anterior skull base olfactory schwannoma. J Neurosurg 2012;32:E3. 